IAC-05-C2.7.10

\title{
ADVANCED MATERIALS FOR SPACE APPLICATIONS
}

\author{
Ruth H. Pater* \\ NASA Langley Research Center, Hampton Virginia 23681, U.S.A. \\ Ruth.H.Pater@NASA.GOV \\ Paul A. Curto \\ NASA Headquarters, Washington, DC 20546, U.S.A. \\ pcurto@hq.nasa.gov
}

\begin{abstract}
$\underline{\text { ABSTRACT }}$
Since NASA was created in 1958, over 6400 patents have been issued to the agency--nearly one in a thousand of all patents ever issued in the United States. A large number of these inventions have focused on new materials that have made space travel and exploration of the moon, Mars, and the outer planets possible. In the last few years, the materials developed by NASA Langley Research Center embody breakthroughs in performance and properties that will enable great achievements in space. The examples discussed below offer significant advantages for use in small satellites, i.e., those with payloads under a metric ton. These include patented products such as LaRC SI, LaRC RP 46, LaRC RP 50, PETI-5, TEEK, PETI-330, LaRC CP, TOR-LM and LaRC LCR (patent pending). These and other new advances in nanotechnology engineering, selfassembling nanostructures and multifunctional aerospace materials are presented and discussed below, and applications with significant technological and commercial advantages are proposed.
\end{abstract}

\subsection{INTRODUCTION}

The Advanced Materials and Processing Branch at NASA Langley has in its inventory approximately 150 issued patents. Most of these new ideas are related to advanced materials that provide enabling technologies for exploration of the moon, Mars, and beyond. Examples of this group of advanced materials are LaRC SI ${ }^{1-3}$, LaRC RP $46^{4}$, LaRC RP 50 5 , LaRC PETI-5 $5^{6-9}$. All of these materials are chemically classified as high temperature, high performance polyimides. They have a high glass transition temperature, can withstand a high temperature for a long period of time in air and in an inert atmosphere, and possess unusual stability when exposed to harsh environmental conditions, including chemicals, moisture, electric fields, mechanical stress, and heat. Because of these attributes, they offer significant advantages for use in small satellites and for space exploration by providing a lightweight and high strength structure. All of these advanced materials can be used as a matrix resin for composites reinforced with a continuous and/or chopped fiber and for a ceramic and/or nanoparticle-filled hybrid material. They are also well suited for use as an advanced coating, a high temperature adhesive, film, foam or molding.

A second group of these new materials focuses particularly on specialized technologies because of their unique 
properties. Examples include LaRC PETI$8^{10}$; LaRC TEEK $^{11}$; LaRC $\mathrm{CP}^{12-15}$; LaRC TOR ${ }^{16-18}$; LaRC PETI-330 ${ }^{19}$; LaRC LCR $^{20}$; self-metallized films ${ }^{21-25}$; low dielectric, high transparency polyimide materials ${ }^{26}$; and electrostrictive graft elastomers. The specialized technologies offered include high temperature, lightweight polyimide foams; colorless polyimides; space environmentally stable polyimides; transfer molding processible polyimide resins; high temperature, liquid crystalline thermoset resins; self-metallization films; and low dielectric constant, high transparency polyimides.

More recently, however, our focus has shifted toward the development of nanotechnologies, smart materials, biologically inspired materials and multifunctional aerospace materials. In the following sections we present the chemistry, properties, and applications of some selected advanced materials.

\subsection{DESCRIPTION AND DISCUSSION}

\subsection{LaRC SI}

LaRC SI is a tough, soluble, thermoplastic copolyimide made from three monomers: 3,4 'oxydianiline (3, 4'-ODA), 4,4'oxydiphthalic anhydride (ODPA) and 3,3'4,4'-biphenyl tetracarboxylic dianhydride (s-BPDA). Figure 1 shows a chemical structure of LaRC SI.

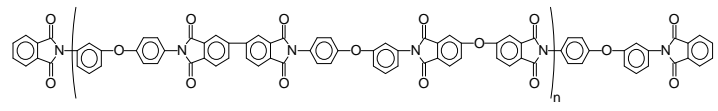

Figure 1. A chemical structure of LaRC SI.

Unlike most wholly aromatic polyimides, which are generally insoluble in most organic solvents, this material is unique in that it is soluble in high boiling point, polar organic solvents, such as N-methyl-2pyrrolidinone (NMP). This unique attribute combined with its flexibility and resistance to a variety of harsh environments makes LaRC SI an enabling material for many technologies. LaRC SI has been shown to offer significant benefits when it is used as a high strength, thin film in electronic flexible circuit boards and cables, as a hot melt adhesive, and as a binder for microcomposite particles such as ceramics and carbon-carbon. Additional applications include protective coatings for electrical insulation, UV resistance, and radiation shielding. LaRC SI is currently being evaluated for biomedical applications. Some LaRC SI products are shown in Figure 2.

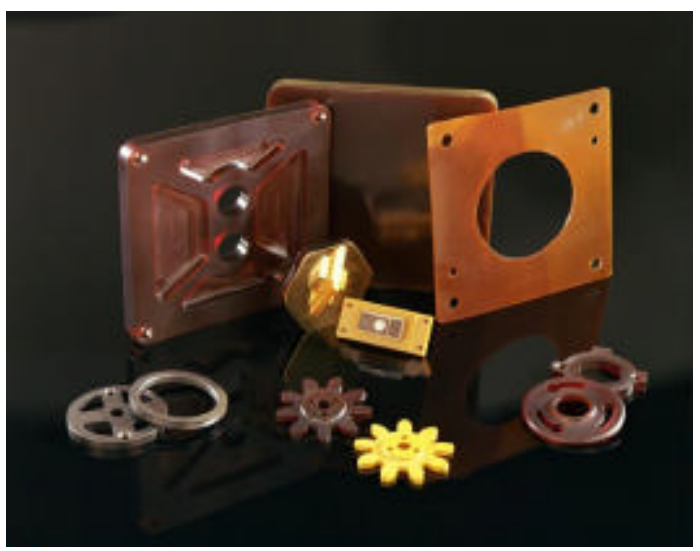

Figure 2. Products of LaRC SI.

\subsection{LaRC RP46}

LaRC RP46 is an ultrahigh performance, ultrahigh temperature, thermosetting polyimide. It is made from three monomers: the mono-methyl ester of 5-norbornene-2,3dicarboxylic acid (NE) as an end-capping agent, 3,4'-ODA, and the dimethyl ester of 3,3'4,4'-benzophenonetetracarboxylic acid (BTDE). Figure 3 illustrates a chemical structure of its imide oligomer. 


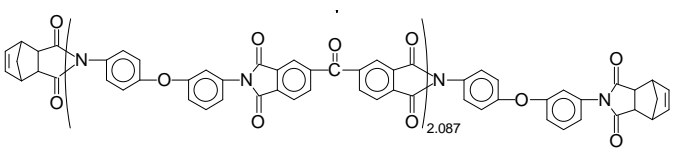

Figure 3. A chemical structure of LaRC RP46.

While polyimides are in general well-known for their high temperature properties, LaRC RP 46 has exceptionally high thermooxidative stability and superior mechanical performance under elevated temperatures. It is one of the world's most heat resistant polymers. LaRC RP 46 is primarily used as a composite matrix resin. Its fiber reinforced composites (graphite, glass, ceramic and other reinforcements) have a use temperature ranging from $-100^{\circ} \mathrm{C}$ to $371^{\circ} \mathrm{C}$ and can withstand up to $816^{\circ} \mathrm{C}$ for a few seconds. RP 46 composites have a glass transition temperature of $392^{\circ} \mathrm{C}$. It is easy to process. Besides being exceptionally heat resistant, LaRC RP46 also has excellent chemical, moisture, and corrosion resistance. It has a low dielectric constant (2.9 at 10 $\mathrm{GHz}$ ) and a low coefficient of thermal expansion.

Because less material is required, LaRC RP 46 offers significant advantages for use in aircraft engine components, space exploration vehicles, small satellites, missiles, and electronic circuit boards by providing 30 to $50 \%$ weight and size savings compared to an epoxy material. Also, its exceptional durability in extremely harsh environments substantially reduces maintenance, repair and down time costs. Figure 4 shows the no-burn-through characteristics and products of LaRC RP 46/carbon composite materials.

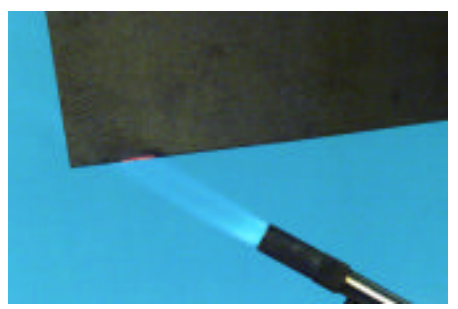

(a)

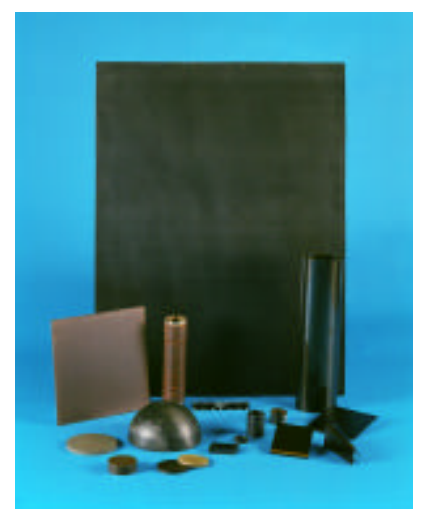

(b)

Figure 4. LaRC RP 46 no- burn-through characteristics (a) and products (b).

\subsection{LaRC RP50}

LaRC RP50 is an ultrahigh temperature, ultrahigh performance, thermosetting polyimide. It is prepared from three monomers: the 5-norbornene-2,3dicarboxylic anhydride (NA), 3,4'-ODA and 3,3'4,4'-benzophenonetetracarboxylic dianhydride (BTDA). Figure 5 shows a chemical structure of its imide oligomer.

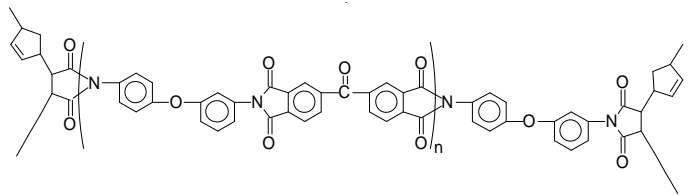

Figure 5. A chemical structure of LaRC RP50.

LaRC RP50 has similar chemistry and properties as LaRC RP46. In addition to its exceptional ability to withstand high temperatures, LaRC RP 50 has excellent moisture, chemical and corrosion resistance. While LaRC RP46 is used primarily as a composite matrix resin, LaRC RP50 is better suited for use as an advanced coating, an 
ultrahigh temperature adhesive, and a high strength thin film. LaRC RP50 can be used in temperatures ranging from $-100^{\circ} \mathrm{C}$ to $371^{\circ} \mathrm{C}$ and for a few minutes up to $850^{\circ} \mathrm{C}$. It has a low dielectric constant $(2.90$ at 10 $\mathrm{GHz})$ and a low dissipation factor (0.001 at $10 \mathrm{GHz}$ ). Like LaRC RP46, the use of LaRC RP50 can yield substantial weight, size and cost savings.

\subsection{LaRC PETI-5}

LaRC PETI-5 is a high temperature, high performance polyimide, which is prepared from four monomers: phenylethynyl phthalic anhydride (PEPA) as an endcapping agent, s-BPDA, 3,4'-ODA, and 1,3bis(3-aminophenoxy)benzene (1,3-bis(3APB)). Figure 6 shows a chemical structure of the imide oligomer of PETI-5 (phenylethynyl-terminated imide with a calculated molecular weight of about 5000 $\mathrm{g} /$ mole).

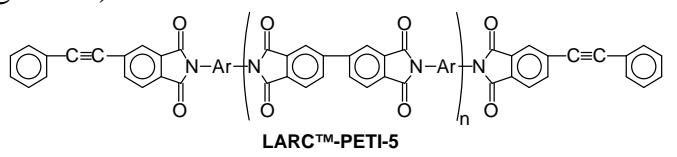

Figure 6. A chemical structure of LaRC PETI-5.

This material was selected as the material of choice for the High Speed Civil Transport program (HSCT) to develop Mach 2.4 commercial passenger airplanes in the early 1990s. A significant engineering database has been created for this material. With a glass transition temperature of $270^{\circ} \mathrm{C}$,

PETI-5 carbon fiber composites have exhibited long-term operation at $150-177^{\circ} \mathrm{C}$. Some of PETI-5's attributes include excellent processibility, high thermal and mechanical properties, excellent toughness, and good solvent resistance. Its adhesives in various forms have the highest flatwise tensile strength (sandwich structure) ever reported. Figure 7 shows a skin stringer panel( $6 \mathrm{ft}$ X $10 \mathrm{ft}$ ) made of a PETI-5/IM 7 composite.

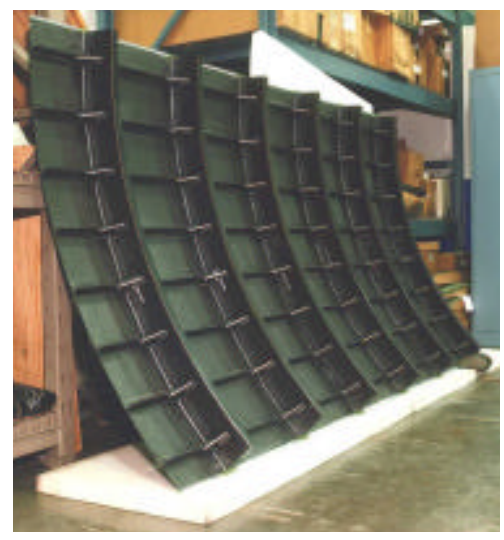

Figure 7. A skin stringer panel made of a PETI-5/IM7 composite.

\subsection{LaRC TEEK}

LaRC TEEK is a high temperature polyimide foam. To date, 25 different polyimides have been foamed using a saltlike process. Figure 8 shows a chemical structure for one of the TEEK polyimides.

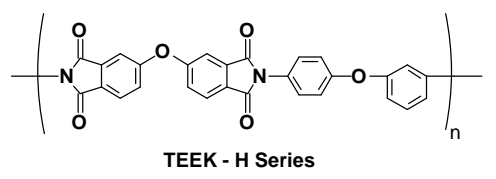

Figure 8. A chemical structure of TEEK

Their densities range from $0.008 \mathrm{~g} / \mathrm{cc}$ to over $0.32 \mathrm{~g} / \mathrm{cc}$. The thermal stability varies from 237 to $321^{\circ} \mathrm{C}$. These polyimide foams exhibit many attributes, which include excellent flammability resistance, hydrolytic stability, limiting oxygen index, compressive strength, thermal insulation, and cryogenic capability. Figure 9 shows typical flame resistant characteristics of LaRC TEEK foams and Table 1 gives their engineering properties. 


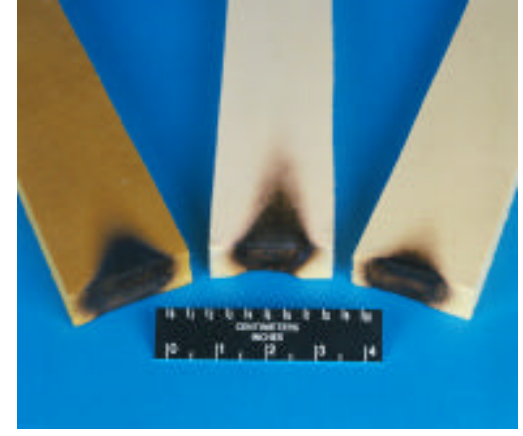

Figure 9. NASA Flammability Test (NHB 8060.1): TEEK-LL, TEEK-HL, and TEEK-HH were tested at $1093^{\circ} \mathrm{C}$ $\left(2000^{\circ} \mathrm{F}\right)$ for $25 \mathrm{sec} . \pm 5 \mathrm{sec}$; specimen size $-30.48 \mathrm{~cm} \times 6.35 \mathrm{~cm} \times 2.54 \mathrm{~cm}$; less than $15.24 \mathrm{~cm}$ burn length $=$ passed test.

Table 1. The Engineering Properties of LaRC TEEK

\begin{tabular}{|c|c|c|c|c|}
\hline Property & Test Method & TEEK-HH & TEEK-HL & TEEK-LL \\
\hline Density & $\begin{array}{c}\text { ASTM } \\
\text { D-3574 (A) }\end{array}$ & $0.08 \mathrm{~g} / \mathrm{cc}$ & $0.032 \mathrm{~g} / \mathrm{cc}$ & $0.032 \mathrm{~g} / \mathrm{cc}$ \\
\hline $\begin{array}{c}\text { Oxygen } \\
\text { Index }\end{array}$ & ASTM & $51 \%$ & $42 \%$ & $49 \%$ \\
\hline \multirow{3}{*}{ Dertical Burn 2863} & & & \\
& NHB 8060.1 & & & \\
& Flame Time & 25 second s & 25 second s & $25 \mathrm{~seconds}$ \\
& Burn Leng th & $0 \mathrm{~cm}$ & $1.5 \mathrm{~cm}$ & $0 \mathrm{~cm}$ \\
Dripping & none & none \\
\hline
\end{tabular}

\subsection{LaRC PETI-330}

LaRC PETI-330 is a high temperature polyimide resin particularly useful for low cost composite fabrication processes such as Resin Transfer Molding (RTM), Resin Infusion (RI), and Vacuum Assisted RTM (VARTM). This resin has not only a low melt viscosity that allows it to flow well under low pressure at elevated temperatures but also melt stability that enables it to fill a large area carbon fiber preform without changing flow characteristics during the composite fabrication processes. These unique features are attributable to its chemistry. It involves the reaction of 2,3,3',4'-biphenyl tetracarboxylic dianhydride (a-BPDA); a mixture of two aromatic diamines, i.e. 1,3-bis(4aminophenoxy)benzene(1,3-bis(4-APB) and 1,3-diaminobenzene(m-PDA); and PEPA as an end-capping agent (Figure 10).

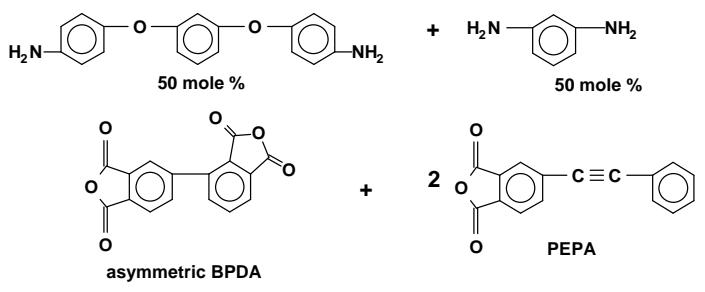

Figure 10. The composition of LaRC PETI-330.

PETI-330 has a glass transition temperature of $330^{\circ} \mathrm{C}$ and a long-term use temperature of $288^{\circ} \mathrm{C}$. Tables 2 and 3 show un-aged and aged composite mechanical properties of PETI-330, respectively.

Table 2. Un-aged PETI-330 Laminate Properties

\begin{tabular}{|c|c|c|c|}
\hline Properties & $\begin{array}{l}\text { Test Temp., } \\
{ }^{\circ} \mathrm{C}\end{array}$ & $\begin{array}{c}\text { PETI-330/ } \\
\text { un-sized AS4 } \\
\text { 8HS }\end{array}$ & $\begin{array}{c}\text { PETI-330/ } \\
\text { un-sized T650 } \\
\text { 8HS }\end{array}$ \\
\hline $\begin{array}{c}\text { Un-notched } \\
\text { Compression } \\
\text { Strength, MPa }\end{array}$ & 23 & 442 & 520 \\
\hline $\begin{array}{c}\text { Open Hole } \\
\text { Compression } \\
\text { Strength, MPa }\end{array}$ & $\begin{array}{c}23 \\
288\end{array}$ & $\begin{array}{l}250 \\
218\end{array}$ & $\begin{array}{l}270 \\
200\end{array}$ \\
\hline $\begin{array}{c}\text { Open Hole } \\
\text { Compression } \\
\text { Modulus, GPa }\end{array}$ & $\begin{array}{c}23 \\
288\end{array}$ & $\begin{array}{l}42 \\
40\end{array}$ & $\begin{array}{l}47 \\
44\end{array}$ \\
\hline $\begin{array}{c}\text { Short Bean } \\
\text { Shear } \\
\text { Strength, MPa }\end{array}$ & $\begin{array}{c}23 \\
232 \\
288\end{array}$ & $\begin{array}{l}38 \\
37 \\
34\end{array}$ & $\begin{array}{l}56 \\
43 \\
35\end{array}$ \\
\hline
\end{tabular}

Table 3. Aged PETI-330 Laminate Properties

\begin{tabular}{|c|c|c|}
\hline $\begin{array}{c}\text { Time at } 288^{\circ} \mathrm{C} \\
\text { in air, hr. }\end{array}$ & $\begin{array}{c}\text { Open Hole } \\
\text { Compression } \\
\text { Strength, MPa }\end{array}$ & $\begin{array}{c}\text { Open Hole } \\
\text { Compression } \\
\text { Modulus, GPa }\end{array}$ \\
\hline 0 & 270 & 47.5 \\
\hline 50 & 262 & 45.3 \\
\hline 100 & 275 & 45.5 \\
\hline 500 & 267 & 44.7 \\
\hline
\end{tabular}

\section{7 $\underline{\text { LaRC TOR }}$}

TOR (Atomic Oxygen Resistant) resins are phosphorus containing polymers. An exemplary chemical structure is shown in Figure 11. 


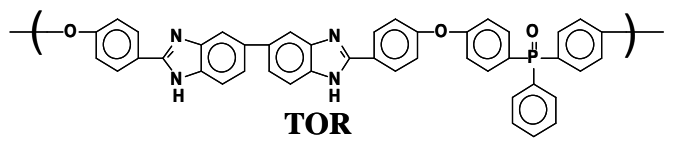

TOR-LM is a copolymer with biphenol poly(arylene ether benzimidazole)s

Figure 11. A chemical structure of LaRC TOR.

The incorporation of phosphorus in an amount of $4.5 \%$ by weight does not change the optical properties of these resins or detract from their glass transition temperatures or bulk mechanical properties. A variety of atomic oxygen and UV resistant products have been made from TOR polymers. These products include threads, MLI blankets, tethers, films and solar array panels (Figure 12). After a 3-year flight simulation test onboard the MIR space station, the TOR film exhibited significantly less erosion than other polymer films such as Kapton ${ }^{\circledR}$ and Teflon ${ }^{\circledR}$ films (Figure 13).
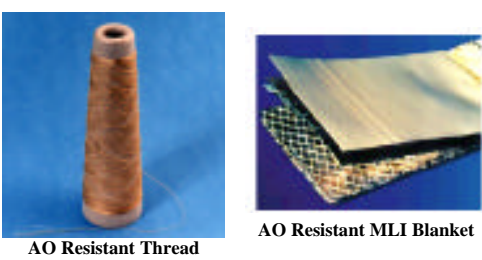

AO Resistant MLI Blanket

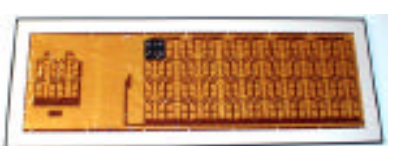

AO Resistant Solar Array Panel
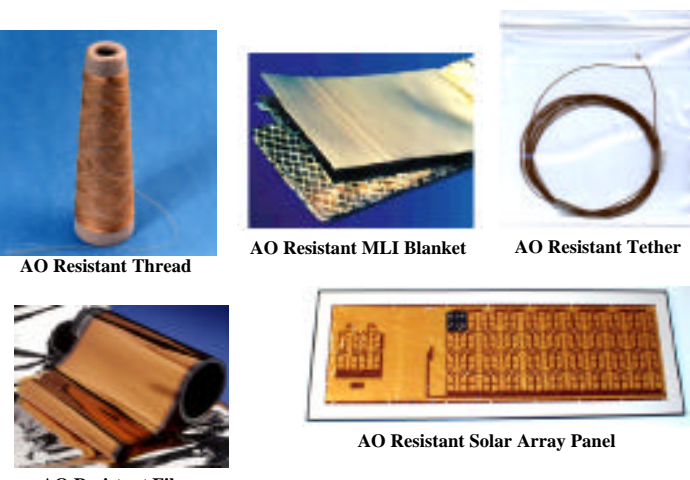

AO Resistant Film

Figure 12. Applications for Atomic Oxygen Resistant (TOR) Thread and Film.

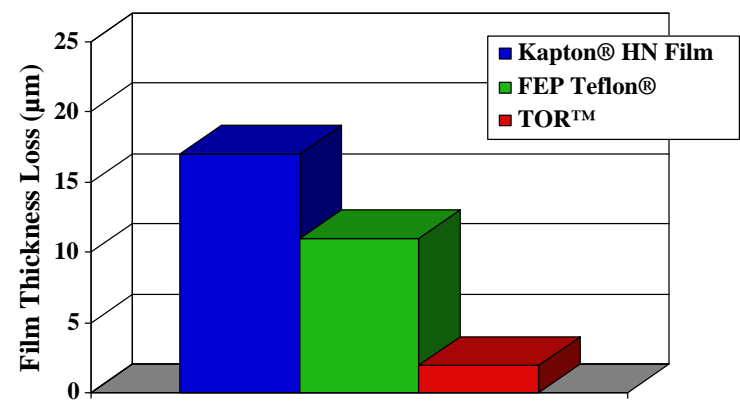

Figure 13. TOR Film Erosion After Simulated 3-Year LEO AO Exposure.

\subsection{LaRC CP}

LaRC CP-1 and LaRC CP-2 are essentially colorless polyimides. Figure 14 shows a chemical structure of LaRC CP-2.

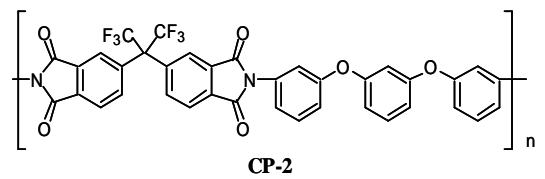

Figure 14. A Chemical Structure of LaRC CP-2.

The thin films made from these polyimides exhibit remarkable optical clarity and high resistance to the UV radiation environment of space, and they have excellent thermal stability at high temperatures. These unique attributes make LaRC CP-1 and LaRC CP-2 enabling technologies for space applications in the areas of solar propulsion and power, solar sails, and communications satellites. In addition, the combination of a low dielectric constant, excellent moisture absorption, solubility in a variety of organic solvents, and high thermal stability offers significant advantages for use in the areas of microelectronics, liquid crystal displays, and antennas for communications. 


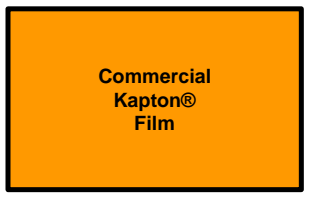

Limited transparency

Limited UV stability

Moisture sensitive

$600^{\circ} \mathrm{F}$ capability

Insoluble

Dielectric constant $=\mathbf{3} .2-4.0$

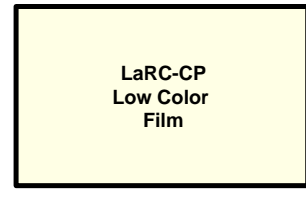

High optical transparency

UV stable

Moisture resistant

$600^{\circ} \mathrm{F}$ capability

Soluble/spray coatable

Dielectric constant $=\mathbf{2 . 5}$

Figure15. A comparison of optical transparency between LaRC CP and Kapton®.

\subsection{PETI-8}

PETI-8 is a high performance phenylethynyl terminated polyimide with a calculated molecular weight of $2500 \mathrm{~g} / \mathrm{mole}$ (see Figure 16). It is prepared from the same monomers as those for PETI-5 discussed in section 2.4. The significant difference between PETI-5 and PETI-8 resides in the calculated molecular weight and the molar ratio of the monomer reactants. At $50 \%$ of the calculated molecular weight of PETI-5, PETI-8 has a significantly lower melt viscosity that enables it to be processible by a simple, low-cost, non-autoclave under a vacuum bag-only pressure at $316^{\circ} \mathrm{C}$ for 8 hours. These processing features make PETI-8 a very attractive material for space applications. It is particularly useful as a high performance adhesive. As seen in Table 4, PETI-8 showed outstanding tensile shear strength for bonding both titanium to titanium and composite to composite adherends. It is also well-suited for bonding a composite skin over a titanium core.

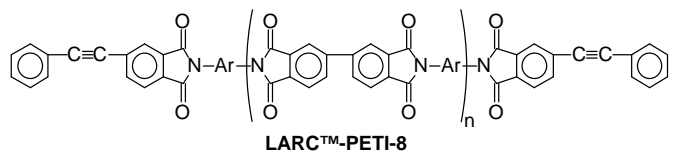

Figure 16. A chemical structure of LaRC PETI-8
Table 4. Initial Adhesive Properties of LaRC PETI-8

\begin{tabular}{|c|c|c|}
\hline Sample Description $^{1}$ & $75^{\circ} \mathrm{F}$ & $350^{\circ} \mathrm{F}$ \\
\hline $\begin{array}{c}\text { Titanium to Titanium } \\
\text { TSS }\end{array}$ & $7400 \mathrm{psi}$ & $6200 \mathrm{psi}$ \\
\hline $\begin{array}{c}\text { Composite to } \\
\text { Composite TSS }\end{array}$ & $6770 \mathrm{psi}$ & \\
\hline $\begin{array}{c}\text { Flatwise Tensile } \\
\text { Strength (Composite } \\
\text { Skins over Ti Core) }\end{array}$ & $1370 \mathrm{psi}$ & \\
\hline
\end{tabular}

${ }^{1}$ Bonding Conditions: Vacuum bag pressure, $316^{\circ} \mathrm{C}, 8$ hours.

${ }^{2}$ Surface treatment: 220 grit silicon carbide, Microjet System, 70 psi.

\subsection{LaRC LCR}

LaRC LCR is a new, wholly aromatic, liquid crystal, thermosetting resin designed for use as a matrix resin for carbon fiber-reinforced cryogenic fuel tanks. It is suitable for pultrusion, RTM, and RFI composite processing and exhibits outstanding barrier properties, high thermal stability and excellent adhesive properties. As shown in Figure 17, its chemical structure comprises a 4-hydroxy-benzoic acid(HBA)/6-hydroxy-2naphthoic acid(HNA) polymer backbone (I) and a phenylethynyl as an end-capper (II).

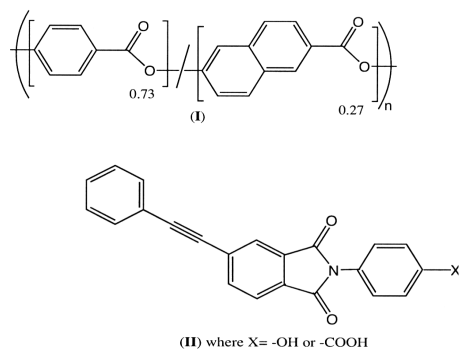

Figure 17. LaRC-LCR polymer backbones and end-capping units.

\section{$\underline{2.11}$ Self-Metallization Process}

A new self-metallization process has been developed with the goals of producing electrically conducting and specularly reflective films. This metallized film process involves a single-stage self-metallizing protocol that includes a single homogeneous 
solution containing both a soluble positivevalent metal complex and the desired polymer resin. During the curing process, migration of reduced metal atoms formed in the bulk of the film occurs to give a metallic surface layer. Additional nano-metal particles remain embedded in the bulk of the film. Compared to the commercially available processes of physical vapor deposition of the metallized surfaces onto a plastic substrate material, the new selfmetallized process is not only considerably more cost effective but it also produces significantly better adhesion of the mirror at the metal-organic interface. This improved adhesion may be explained by better mechanical interlocking or by the formation of chemical bonds between the metal and organic substrate. Polymer films containing various metals that include $\mathrm{Ag}, \mathrm{Au}, \mathrm{Pd}$, and $P t$ have been prepared with various levels of specular reflectivity and surface resistivity.

\subsection{Low Dielectric, High Transparency Polyimide}

This invention features a low dielectric, high transparency polyimide film prepared by reacting 1,6-hexamethylenediamine (HMDA) with 2,2'-bis-(3,4-dicarboxyphenyl)hexafluoropropane dianhydride (6FDA) followed by thermal imidization under an inert atmosphere. The polyimide has a dielectric constant ranging from 2.4 to 2.5 at 8.2 to $12.4 \mathrm{GHz}$, a high degree of optical transparency, a high degree of durability, and lower fabrication cost relative to other membrane optics materials. Proposed uses for this highly transparent, flexible film include membrane optics, windows and computer touch screens, fiberoptic coating, waveguide coating and polymer coatings for lenses.

\subsection{CONCLUSION}

Researchers at the Advanced Materials and Processing Branch of NASA Langley have been actively developing a wide variety of novel, lightweight, high performance, high temperature advanced materials since the 1970s. Most of the 150 patents issued are related to polyimide materials and processes for making them. We have presented the chemistry, properties, and applications for some of these advanced materials and specialized technologies. Examples presented are LaRC SI, LaRC RP46, LaRC RP50, LaRC PETI-5, LaRC TEEK, LaRC PETI-330, TOR-LM, LaRC CP, LaRC PETI-8, LaRC LCR, a Self-Metallization Process, and a Low Dielectric, High Transparency Polyimide. Some of these materials embody breakthroughs in performance and properties, while the others exhibit unique, one-of-a- kind properties that no other materials can duplicate. Most of these materials can be used as a composite matrix resin, a high temperature adhesive, an advanced coating, a thin film, and a molding article. The rest are better suited for specialized applications, such as atomic oxygen resistant films, thermal/cryogenic insulation foams, cryogenic fuel tanks, and colorless polyimide films. Because of their unique properties, these advanced materials and specialized technologies offer significant advantages for space exploration and other non-aerospace applications.

\subsection{REFERENCES}

1. R. G. Bryant, Process for Preparing a Tough, Soluble, Aromatic,
Thermoplastic Copolyimide, US Patent 5,639,850 (1997). 
2. R. G. Bryant, Tough, Soluble, Aromatic Thermoplastic Copolyimides, US Patent 5,741,883 (1998).

3. R. G. Bryant, Tough Soluble Aromatic Thermoplastic Copolyimides, US Patent 6,048,959 (2000).

4. R. H. Pater, Low Toxicity High Temperature PMR Polyimide, US Patent 5,171,822 (1992).

5. R. H. Pater, Heat, Moisture, and Chemical Resistant Polyimide Compositions and Methods for Making and Using Them, US Patent 6,777,525 B2 (2004).

6. P. M. Hergenrother, R. G. Bryant, B. J. Jensen, and S. J. Havens, Phenylethynyl Terminated Imide Oligomers, US Patent 5,412,066 (1995).

7. P. M. Hergenrother and J. G. Smith, Jr., Imide Oligomers Endcapped with Phenylethynyl Phthalic Anhydrides and Polymers Therefrom, US Patent 5,567,800 (1996).

8. P. M. Hergenrother and J. G. Smith, Jr., Phenylethynyl Phthalic Anhydride, US Patent 5,681,967 (1997).

9. P. M. Hergenrother and J. G. Smith, Jr., Imide Oligomers Endcapped with Phenylethynl Phthalic Anhydrides and Polymers Therefrom, US Patent 5,760,168 (1998).

10. B. J. Jensen, Copolyimides Prepared from 3,4'-Oxydianiline and 1,3-Bis(3aminophenoxy)benzene with 3,3'-4,4'Biphenylcarboxylic Dianhydride Having Reactive Endgroups, US Patent 5,644,022 (1997).

11. E. S. Weiser, T. L. St. Clair, Y. Echigo, and H. Kaneshiro, Aromatic Polyimide Foam, US Patent 6,133,330 (2000).

12. A. K. St. Clair and T. L. St. Clair, Process for Preparing Highly Optically Transparent/Colorless Aromatic Polyimide Film, US Patent 4,603,061 (1986).

13. A. K. St. Clair and T. L. St. Clair, Process for Preparing Essentially Colorless Polyimide Film Containing Phenoxy-Linked Diamines, US Patent 4,595,548 (1986).
14. A. K. St. Clair, T. L. St. Clair and W. P. Winfree, Structures from Low Dielectric Polyimides, US Patent 5,338,826 (1994).

15. A. K. St. Clair, T. L. St. Clair, and W. P. Winfree, Low Dielectric Polyimides, US Patent 5,428,102 (1995).

16. J. W. Connell, P. M. Hergenrother, and J. G. Smith, Jr., Di(hydroxyphenyl)benzimidazole Monomers, US Patent 5,245,044 (1993).

17. J. W. Connell, P. M. Hergenrother, and J. G. Smith, Jr., Polybenzimidazole via Aromatic Nucleophilic Displacement, US Patent 5,317,078 (1994);

18. J. W. Connell, P. M. Hergenrother, and J. G. Smith, Jr., Polybenzimidazoles via Aromatic Nucleophilic Displacement, US Patent 5,412,059 (1995).

19. J. W. Connell, J. G. Smith, Jr., and P. M. Hergenrother, Composition of and Method for Making High Performance Resins for Infusion and Transfer Molding Process, US Patent 6,359,107 B1 (2002).

20. T. J. Dingemans, S. van der Zwaag, A. Knijnenberg, E. S. Weiser, and B. J. Jensen, Novel Liquid Crystal Thermoset Resins for Cryogenic Fuel Tank Applications, The $24^{\text {th }}$ International Congress of the Aeronautical Sciences, 2004, Patent Pending.

21. R. A. Frosch, L. T. Taylor, A. K. St. Clair, V. C. Carver, and T. A. Furtsch, Electrically Conductive Palladium Containing Polyimde Films, US Patent 4,311,615 (1982).

22. J. D. Rancourt, D. M. Stoakley, M. L. Caplan, A. K. St. Clair, and L. T. Taylor, Electrically Conductive Polyimides Containing Silver Trifluoroacetylacetonate, US Patent 5,520,960 (1996).

23. M. L. Caplan, D. M. Stoakley, and A. K. St. Clair, Electrically Conductive Polyimide Film Containing Gold (III) Ions, Composition, and Process of Making, US Patent 5,575,955 (1996).

24. D. W. Thompson, M. L. Caplan, and A. K. St. Clair, Reflective Self-Metallizing 
Polyimide Films, US Patent 5,677,418 (1997).

25. R. E. Southward, D. W. Thompson, A. K. St. Clair, and D. M. Stoakley, Reflective Silvered Polyimide Films via In Situ Thermal Reduction Silver (I)
Complexes, US Patent 6,019,926 (2000).

26. M. Herzog, D. M. Stoakley, C. Fay, A Low Dielectric, High Transparency Polyimide Material, LAR16866-1. 